\title{
Src tyrosine kinase mediates endothelin-1-induced early growth response protein-1 expression via MAP kinase-dependent pathways in vascular smooth muscle cells
}

\author{
ESTELLE R. SIMO-CHEYOU ${ }^{1,2}$, GEORGE VARDATSIKOS ${ }^{1}$ and ASHOK K. SRIVASTAVA ${ }^{1-3}$ \\ ${ }^{1}$ Laboratory of Cellular Signaling, Montreal Diabetes Research Center, \\ Research Center - University of Montreal Hospital Center, Montreal, QC H2X 0A9; \\ Departments of ${ }^{2}$ Nutrition and ${ }^{3}$ Medicine, Faculty of Medicine, University of Montreal, Montreal, QC H3G 2M1, Canada
}

Received May 10, 2016; Accepted October 4, 2016

DOI: $10.3892 /$ ijmm.2016.2767

\begin{abstract}
We have previously demonstrated that the nonreceptor protein tyrosine kinase (NR-PTK) c-Src is an upstream regulator of endothelin-1 (ET-1) and angiotensin II-induced activation of protein kinase $\mathrm{B}$ (PKB) signaling in vascular smooth muscle cells (VSMCs). We have also demonstrated that ET-1 potently induces the expression of the early growth response protein-1 (Egr-1), a zinc finger transcription factor that is overexpressed in models of vascular diseases, such as atherosclerosis. However, the involvement of c-Src in ET-1-induced Egr-1 expression has not yet been investigated and its role in mitogen-activated protein kinase (MAPK) signaling remains controversial. Therefore, the aim of the present study was to examine the role of c-Src in the ET-1-induced phosphorylation of extracellular signal-regulated kinase (ERK)1/2, c-Jun $\mathrm{N}$-terminal kinase (JNK) and p38 MAPK, 3 key members of the MAPK family and in the regulation of Egr-1 expression in rat aortic A10 VSMCs. ET-1 rapidly induced the phosphorylation of MAPKs, as well as the expression of Egr-1; however, treatment of the VSMCs with PP2, a specific pharmacological inhibitor of c-Src, dose-dependently reduced the phosphorylation of the 3 MAPKs and the expression of Egr-1 induced by ET-1. Furthermore, in mouse embryonic fibroblasts (MEFs) deficient in c-Src (SYF), the ET-1-induced Egr-1 expression and MAPK phosphorylation were significantly suppressed, as compared to MEFs expressing normal Src levels. These results suggest that c-Src plays a critical role in mediating ET-1-induced MAPK phosphorylation and Egr-1 expression in VSMCs.
\end{abstract}

Correspondence to: Dr Ashok K. Srivastava, Laboratory of Cellular Signaling, Centre de Recherche-Centre Hospitalier de l'Université de Montréal, 900 Rue Saint-Denis Street, Montréal, QC H2X 0A9, Canada

Email: ashok.srivastava@umontreal.ca

Key words: endothelin-1, mitogen-activated protein kinase, c-Src, early growth response protein-1

\section{Introduction}

Alterations in vascular smooth muscle cell (VSMC) growth, migration, proliferation and plasticity are believed to contribute to vascular dysfunction associated with cardiovascular diseases, such as hypertension, atherosclerosis and stenosis following angioplasty $(1,2)$. Aberrant increases in the plasma levels of vasoactive peptides are a hallmark of these vascular diseases. The involvement of the vasoconstrictor endothelin-1 (ET-1) in the activation of signaling events intimately linked to the migration and proliferation of VSMCs has been documented over the past years $(3,4)$. In VSMCs, ET-1 exerts its growth-promoting effects through the activation of its seven transmembrane domain guanine nucleotide-binding protein (G protein)coupled receptor (GPCR) (5), ETA receptor. GPCR stimulation leads to the activation of several downstream signaling cascades, which include members of the mitogen-activated protein kinase (MAPK) family, as well as the phosphatidylinositol 3-kinase (PI3-K)/protein kinase B (PKB) pathway (6).

MAPKs constitute a family of serine/threonine protein kinases which are widely conserved among eukaryotes, and are involved in many cellular responses, such as cell motility, proliferation, differentiation and survival $(7,8)$. To date, the most extensively studied members of the MAPK family include extracellular signal-regulated kinase (ERK)1/2, c-Jun N-terminal kinase (JNK), and p38 MAPK $(7,8)$, which are stimulated by mitogens, such as polypeptide growth factors [insulin-like growth factor (IGF)-1, platelet-derived growth factor (PDGF) and colony stimulating factor-1 (CSF-1)], as well as by insulin and phorbol 12-myristate 13-acetate (PMA). Substantial evidence exists to support a role of MAPK activation in inducing cell growth and hypertrophy in aortic and mesenteric artery-derived VSMCs (9-12).

The early growth response factor-1 (Egr-1) is a zinc finger transcription factor that regulates the transcription of several genes involved in cardiovascular functions $(13,14)$. Egr-1 has been suggested to contribute to the progression of vascular disease processes, such as intimal thickening following vascular injury (15), atherosclerosis and cardiac hypertrophy $(16,17)$. We recently reported the upregulation of Egr-1 levels in response to ET-1 in VSMCs (18); however, little is known about the 
molecular mechanisms that transduce these signals into an increase in Egr-1 expression.

We have recently demonstrated that c-Src, also known as Src or $\mathrm{p} 60^{\mathrm{c}-\mathrm{Src}}$, is a non-receptor tyrosine kinase (NR-TK) that plays a key role in mediating ET-1-induced PKB phosphorylation, cell hypertrophy and proliferation (19). However, the involvement of c-Src in ET-1-induced Egr-1 expression has not yet been investigated and its role in MAPK signaling remains controversial (38).

Therefore, in the present study, by using a pharmacological inhibitor of c-Src and cells deficient in c-Src, we examined the role of c-Src as an upstream regulator of ET-1-induced ERK1/2, JNK and p38 MAPK phosphorylation, as well as its involvement in the regulation of Egr-1 expression in VSMCs.

\section{Materials and methods}

\section{Materials}

Chemicals. Cell culture reagents were purchased from Gibco (Burlington, ON, USA). ET-1 was purchased from American Peptide (Sunnyvale, CA, USA). 4-Amino-5-(4-chlorophenyl)7-(t-butyl)pyrazole(3,4-d)pyrimidine (PP2; src inhibitor), 4-amino-7-phenylpyrazole(3,4-d) pyrimidine (PP3; inactive analog of src inhibitor) and PD98059 (MEK inhibitor), SP600125 (JNK inhibitor), were purchased from Calbiochem (San Diego, CA, USA). The enhanced chemiluminescence (ECL) detection system kit was purchased from Amersham Pharmacia Biotech (Baie d'Urfé, QC, Canada).

Antibodies. Phospho-SAPK/JNK (Thr183/Tyr185) (Cat. no. 4668), phospho-p38 MAPK (Thr180/Tyr182) (Cat. no. 4511S), total SAPK/JNK (Cat. no. 9252), $\beta$-tubulin (Cat. no. 2146S), total glyceraldehyde 3-phosphate dehydrogenase (GAPDH) (Cat. no. 5174) and anti-rabbit IgG, horseradish peroxidase-linked secondary antibody (Cat. no. 7074) were procured from Cell Signaling Technology (Danvers, MA, USA). Phospho-ERK1/2 (Thr202/Tyr204) (Cat. no. sc-16982-R), total ERK (Cat. no. sc-154), total p38 MAPK (Cat. no. sc-7972), total Egr-1 (Cat. no. sc-110) and anti-mouse IgG, horseradish peroxidase-linked secondary antibody (Cat. no. sc-2005) were purchased from Santa Cruz Biotechnology, Inc. (Santa Cruz, CA, USA).

\section{Methods}

Cell culture. Rat aorta A-10 VSMCs (CRL-1476; ATCC, Manassas, VA, USA) were maintained in $75-\mathrm{cm}^{2}$ flasks culture with Dulbecco's modified Eagle's medium (DMEM) containing $10 \%$ fetal bovine serum and antibiotics at $37^{\circ} \mathrm{C}$ in a humidified atmosphere of $5 \% \mathrm{CO}_{2}$, as previously described (19). The cells were passed upon reaching confluence with $0.5 \%$ trypsin-containing $0.2 \%$ EDTA and plated in $60 \mathrm{~mm}$ dishes. The cells were grown to $90 \%$ confluence and incubated in serum-free DMEM $18 \mathrm{~h}$ prior to the treatments. Mouse embryonic fibroblasts (MEFs) deficient for c-Src, Yes and Fyn (SYF) (CRL-2459) and expressing endogenous wild-type c-Src, but not Yes and Fyn $\left(\mathrm{Src}^{+/+}\right)$(CRL-2497) (both from ATCC) were cultured and used for the experimentats in the same manner as the A10 VSMCs.

Cell lysis and immunoblotting. The cells incubated in the absence or presence of various agents were washed 3 times with ice-cold phosphate-buffered saline (PBS) and lysed in $200 \mu \mathrm{l}$ of lysis buffer [25 mM Tris-HCl, pH 7.5, $25 \mathrm{mM} \mathrm{NaCl}, 1 \mathrm{mM}$ $\mathrm{NaOV}, 10 \mathrm{mM}$ Na fluoride, $10 \mathrm{mM}$ Na-pyrophosphate, $2 \mathrm{mM}$ benzamidine, $2 \mathrm{mM}$ ethylenebis(oxyethylenenitrilo)-tetraacetic acid, $2 \mathrm{mM}$ ethylenediamine tetra acetic acid, $1 \mathrm{mM}$ PMSF, $1 \%$ Triton $\mathrm{X}-100,0.1 \%$ sodium dodecyl sulfate (SDS) and $1 \%$ protease inhibitor cocktail (PIC)] on ice. Cell lysates were centrifuged at $12,000 \mathrm{x} \mathrm{g}$ for $10 \mathrm{~min}$ at $4^{\circ} \mathrm{C}$. Protein concentrations were measured by Bradford assay. Equal amounts of protein were subjected to $7.5 \%$ SDS-polyacrylamide gel electrophoresis (PAGE), transferred onto PVDF membranes (Millipore, Billerica, MA, USA) and incubated with the respective primary antibodies. The antigen-antibody complex was detected by horseradish peroxidase-conjugated secondary antibody and protein bands were visualized by ECL. The intensity of specific bands was quantified using Quantity One Image software (Bio-Rad, Hercules, CA, USA).

Egr-1 nuclear extraction protocol. The cells incubated in the absence or presence of pharmacological agents were washed twice in ice-cold PBS and lysed in $500 \mu \mathrm{l}$ of buffer solution containing $10 \mathrm{mM}$ HEPES, $10 \mathrm{mM} \mathrm{KCl,} 0.1 \mathrm{mM}$ EDTA, $0.1 \mathrm{mM}$ EGTA, $1 \mathrm{mM}$ PMSF, $1 \mathrm{mM}$ protease cocktail inhibitor and $1 \mathrm{mM} \mathrm{NaOV}$ as previously described (20). Briefly, lysates were placed on ice for 15 min prior to the addition of $10 \%$ NP-40 detergent. Lysates were then vortexed for $10 \mathrm{sec}$ at highest setting before centrifugation at $18,000 \mathrm{x}$ for $4 \mathrm{~min}$ at $4^{\circ} \mathrm{C}$. The pellet was resuspended in $60 \mu \mathrm{l}$ of buffer containing $10 \mathrm{mM}$ HEPES, $400 \mathrm{mM} \mathrm{NaCl}, 0.1 \mathrm{mM}$ EDTA, $0.1 \mathrm{mM}$ EGTA, $1 \mathrm{mM}$ PMSF, $1 \mathrm{mM}$ protease cocktail inhibitor and $1 \mathrm{mM} \mathrm{NaOV}$. The suspension was sonicated by performing 6 cycles at $10 \mathrm{sec} /$ cycle with $30 \mathrm{sec}$ intervals and then centrifuged at $18,000 \mathrm{x}$ g for $5 \mathrm{~min}$ at $4^{\circ} \mathrm{C}$. The pellet was discarded and the supernatant, corresponding to the nuclear fraction, was collected. Protein concentrations were measured by Bradford assay for subsequent immunoblotting with Egr-1 antibody. This antibody detects Egr-1 protein as a doublet, since Egr-1 can also be phosphorylated (21), it is possible that this doublet represents the phosphorylated and dephosphorylated forms of the Egr-1.

Preparation of $c D N A$. Following incubation, total RNA was isolated using TRIzol reagent (Life Technologies, Burlington, ON, USA). The RNA concentration was quantified with the Eppendorf BioPhotometer D30 (Eppendorf, Mississauga, ON, Canada). Absorbances were measured at wavelengths of 260 and $280 \mathrm{~nm}$. The purity of RNA preparation was confirmed when the ratio A260/A280 was comprised in the range 1.8-2.0. Subsequently, the cDNA was synthesized from $1 \mu \mathrm{g}$ of total pure RNA using High Capacity RNA-tocDNA kit (Applied Biosystems, Grand Island, NY, USA) as per the manufacturer's instructions.

Quantitative polymerase chain reaction ( $q P C R)$. qPCR was performed using SYBR-Green (Life Technologies, Grand Island, NY, USA) with $1 \mu \mathrm{l}$ of cDNA in a $20 \mu 1$ reaction. Amplification was performed using 7500 Fast RT-PCR system (Applied Biosystems, Grand Island, NY, USA). Sequences used to design Egr-1 primers were as follows: forward, 5'-CTG CTTCATCGTCTTCCTCTG-3' and reverse, 5'-GTCAGTG TTGGGAGTAGGAAAG-3'. Egr-1 mRNA expression was measured and normalized to $\beta$-actin mRNA levels using primers: forward, 5'-TCTTCCAGCСТTCСТTCCT-3' and reverse, 5'-CAGCACTGTGTTGGCATAGA-3'. 

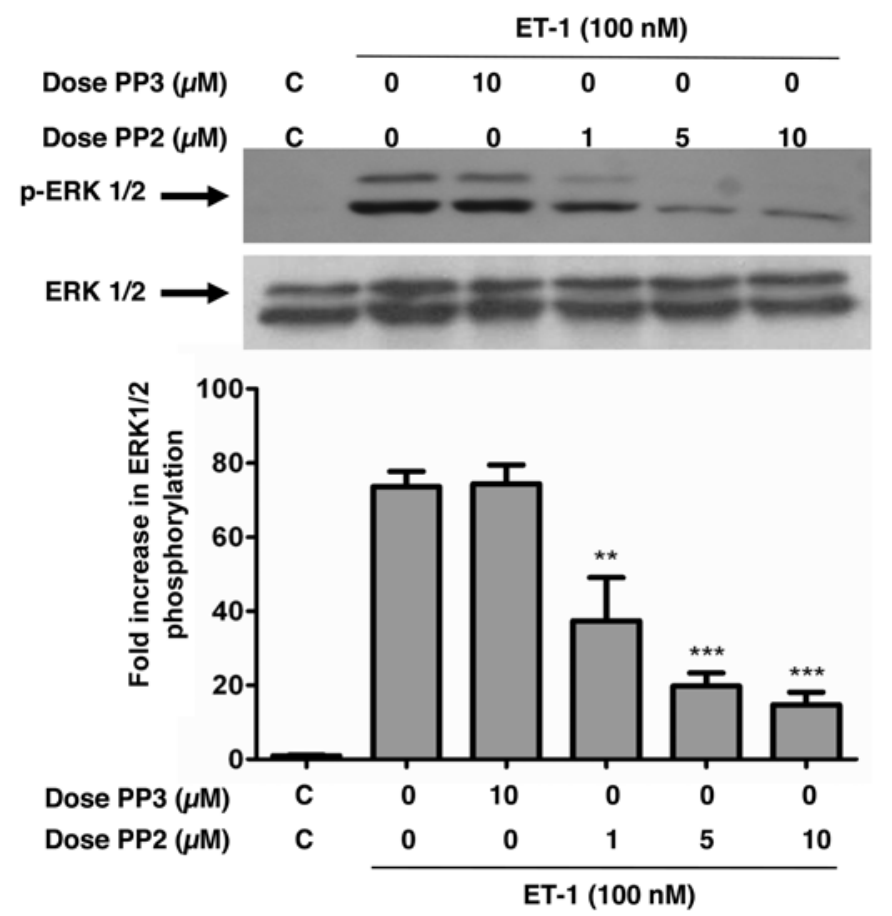

Figure 1. Pharmacological blockade of c-Src abolishes endothelin-1 (ET-1)induced extracellular signal-regulated kinase (ERK) $1 / 2$ phosphorylation in A10 vascular smooth muscle cells (VSMCs). Serum-starved quiescent A10 VSMCs were pre-treated in the absence $(0)$ or presence of $10 \mu \mathrm{M} \mathrm{PP} 3$ or the indicated concentrations of PP2 for 30 min, followed by stimulation with ET-1 (100 nM) for 5 min. Cell lysates were immunoblotted with phosphospecific-Thr202/Tyr204-ERK1/2 antibodies. Blots were also analyzed for total ERK. Bar diagrams in each panel represent average data quantified by densitometric scanning of immunoblots shown in the same panel. Values are the means \pm SE of 3 independent experiments and are expressed as a fold increase in phosphorylation, where basal phosphorylation observed (C, no stimulation) is defined as 1 . A value of $\mathrm{P}<0.05$ was considered as statistically significant vs. ET-1 stimulation alone. ${ }^{*} \mathrm{P}<0.05,{ }^{* *} \mathrm{P}<0.001$ and ${ }^{* * *} \mathrm{P}<0.0001$.

Statistical analysis. The results presented are the means $\pm \mathrm{SE}$ of 3 or more independent experiments. Statistical analyses were performed by analysis of variance (one-way ANOVA), followed by Dunnett's multiple comparison post test, where applicable, using Prism 5 (GraphPad Software Inc., La Jolla, CA, USA). P-values $<0.05$ were considered to indicate statistically significant differences.

\section{Results}

Inhibition of $c$-Src attenuates the ET-1-induced phosphorylation of ERK1/2 in A10 VSMCs. We previously demonstrated that c-Src plays a critical role in mediating ET-1 and angiotensin-II (Ang-II)-induced PKB phosphorylation through the Tyr418 phosphorylation of c-Src in VSMCs (19); however, the involvement of c-Src in the ET-1-induced MAPK phosphorylation remains controversial (22). Therefore, by using PP2, a specific blocker of the Src family of PTK (19), in this study, we investigated the role of c-Src in ERK1/2 phosphorylation in A10 VSMCs. ET-1 potently enhanced the phosphorylation of ERK1/2 (Fig. 1). However, pre-treatment of the A10 VSMCs with PP2 for 30 min dose-dependently attenuated the ET-1induced phosphorylation of ERK1/2, whereas treatment with PP3, an inactive analog of PP2, had no effect. No alterations in
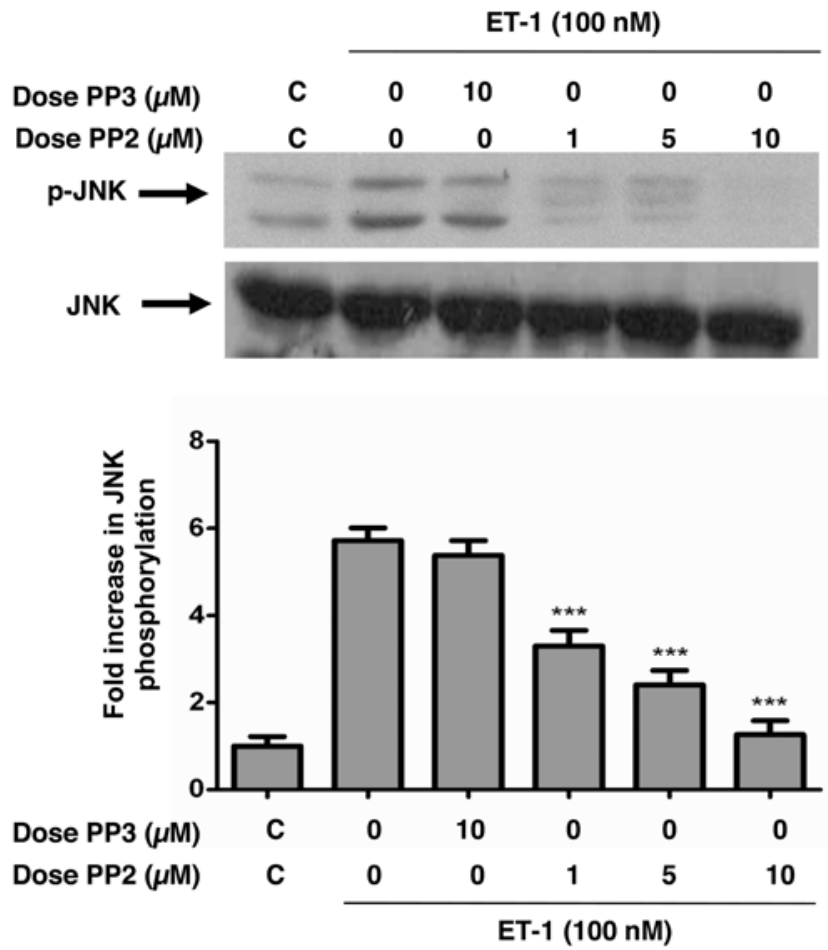

Figure 2. Pharmacological blockade of c-Src attenuates endothelin-1 (ET-1)induced c-Jun N-terminal kinase (JNK) phosphorylation in A10 vascular smooth muscle cells (VSMCs). Serum-starved quiescent A10 VSMCs were pre-treated in the absence (0) or presence of $10 \mu \mathrm{M} \mathrm{PP} 3$ or the indicated concentrations of PP2 for $30 \mathrm{~min}$, followed by stimulation with ET-1 (100 nM) for $5 \mathrm{~min}$. Cell lysates were immunoblotted with phospho-specific-Thr183/Tyr185-JNK antibodies. Blots were also analyzed for total JNK. Bar diagrams in each panel represent average data quantified by densitometric scanning of immunoblots shown in the same panel. Values are the means \pm SE of 3 independent experiments and are expressed as a fold increase in phosphorylation, where basal phosphorylation observed (C, no stimulation) is defined as 1 . A value of $\mathrm{P}<0.05$ was considered as statistically significant vs. ET-1 stimulation alone. ${ }^{*} \mathrm{P}<0.05$, ${ }^{* * *} \mathrm{P}<0.001$ and ${ }^{* * *} \mathrm{P}<0.0001$.

the total amounts of ERK1/2 were observed under these experimental conditions.

ET-1-induced phosphorylation of JNK/SAPK and p38 MAPK is attenuated by $c$-Src tyrosine kinase inhibition in A10 VSMCs. JNK and p38 MAPK are both expressed in VSMCs and are activated by both Ang-II and ET-1 $(22,23)$; however, the role of $\mathrm{c}$-Src in mediating this activation remains controversial. Therefore, in this study, by using PP2, we investigated the role of c-Src in JNK and p38 MAPK phosphorylation in A10 VSMCs. ET-1 potently enhanced the phosphorylation of JNK (Fig. 2) and p38 MAPK (Fig. 3). Treatment of the A10 VSMCs with PP2 for 30 min prior to ET-1 stimulation dose-dependently inhibited JNK (Fig. 2) and p38 MAPK (Fig. 3) phosphorylation induced by ET-1. PP3, on the other hand, was unable to inhibit JNK or p38 MAPK phosphorylation induced by the peptide. No alterations in the total amounts of JNK or p38 MAPK were observed under these experimental conditions.

Inhibition of c-Src tyrosine kinase attenuates ET-1-induced Egr-1 expression in A10 VSMCs. Previous studies have suggested that the transcription factor, Egr-1, plays an important role in multiple processes linked to vascular pathobiology, including the progression of atherosclerotic lesions and neointimal thickening after 


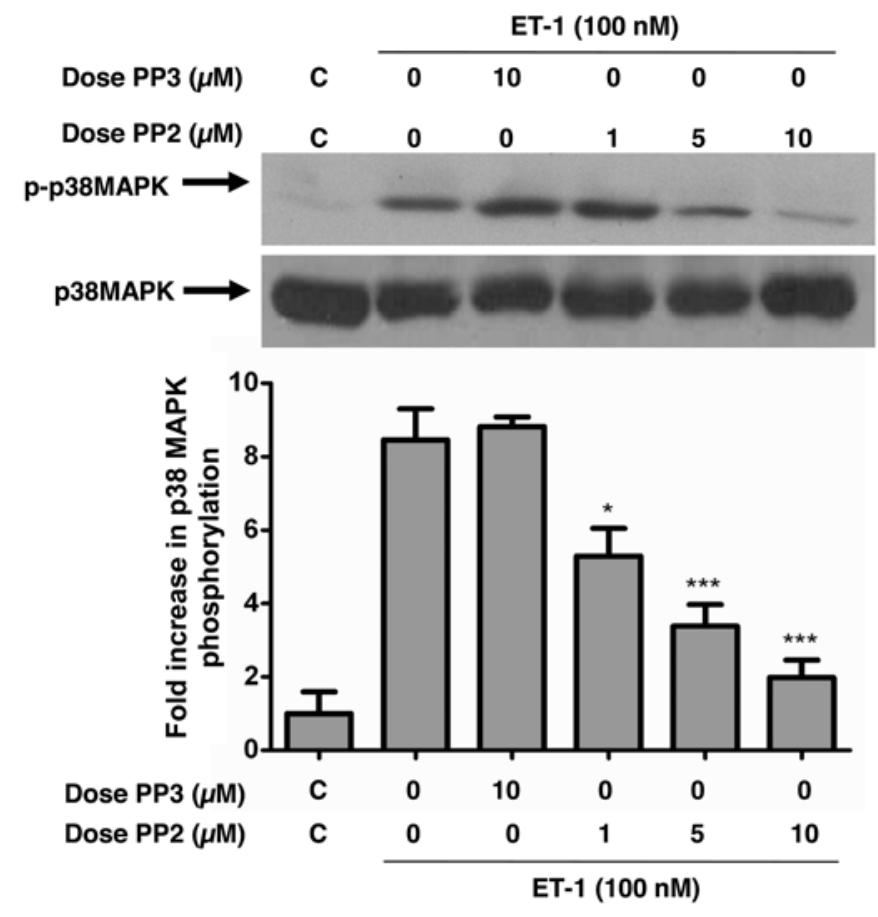

Figure 3. Pharmacological blockade of c-Src attenuates endothelin-1 (ET-1)induced p38 MAPK phosphorylation in A10 vascular smooth muscle cells (VSMCs). Serum-starved quiescent A10 VSMCs were pre-treated in the absence (0) or presence of $10 \mu \mathrm{M}$ PP3 or the indicated concentrations of PP2 for $30 \mathrm{~min}$, followed by stimulation with ET-1 $(100 \mathrm{nM})$. Cell lysates were immunoblotted with phospho-specific-Thr180/Tyr182-p38 MAPK antibodies. Blots were also analyzed for total p38 MAPK. Bar diagrams in each panel represent average data quantified by densitometric scanning of immunoblots shown in the same panel. Values are the means \pm SE of 3 independent experiments and are expressed as a fold increase in phosphorylation, where basal phosphorylation observed (C, no stimulation) is defined as 1 . A value of $\mathrm{P}<0.05$ was considered as statistically significant vs. ET-1 stimulation alone. ${ }^{*} \mathrm{P}<0.05,{ }^{* *} \mathrm{P}<0.001$ and ${ }^{* * *} \mathrm{P}<0.0001$.

vascular injury (24-26). We have recently demonstrated that ET-1 upregulates the expression of Egr-1 in a calcium/calmodulindependent manner (18); yet no studies to date have examined the role of c-Src in this process, at least to the best of our knowledge. Therefore, we wished to determine the involvement of c-Src in the ET-1-induced expression of Egr-1. Stimulation of the serum-starved VSMCs with 100 nM ET-1 time-dependently increased the protein expression of Egr-1 (Fig. 4A). Treatment of the cells with $10 \mu \mathrm{M}$ PP2 prior to stimulation with ET-1 significantly decreased the ET-1-induced Egr-1 expression in these cells (Fig. 4B), suggesting a role of c-Src in Egr-1 expression. Treatment with PP3 did not have any effect.

c-Src knockdown decreases ET-1-induced ERK1/2, JNK and p38 MAPK phosphorylation, as well as Egr-1 expression. To further confirm the role of c-Src PTK in ET-1-induced MAPK activation, we utilized MEFs harvested from mouse embryos which have a functional null mutation in both alleles of the Src family PTK coding for c-Src (SYF) (27). MEFs expressing endogenous wild-type c-Src $\left(\mathrm{Src}^{+/+}\right)$were used as the control cells in these experiments. ET- 1 treatment resulted in a time-dependent increase in the phosphorylation of ERK1/2 (Fig. 5A), JNK (Fig. 5B) and p38 MAPK (Fig. 5C) in the $\mathrm{c}-\mathrm{Src}^{+/+}$cells; however, this response was blunted in the SYF cells. No alterations in the total amounts of ERK1/2, JNK
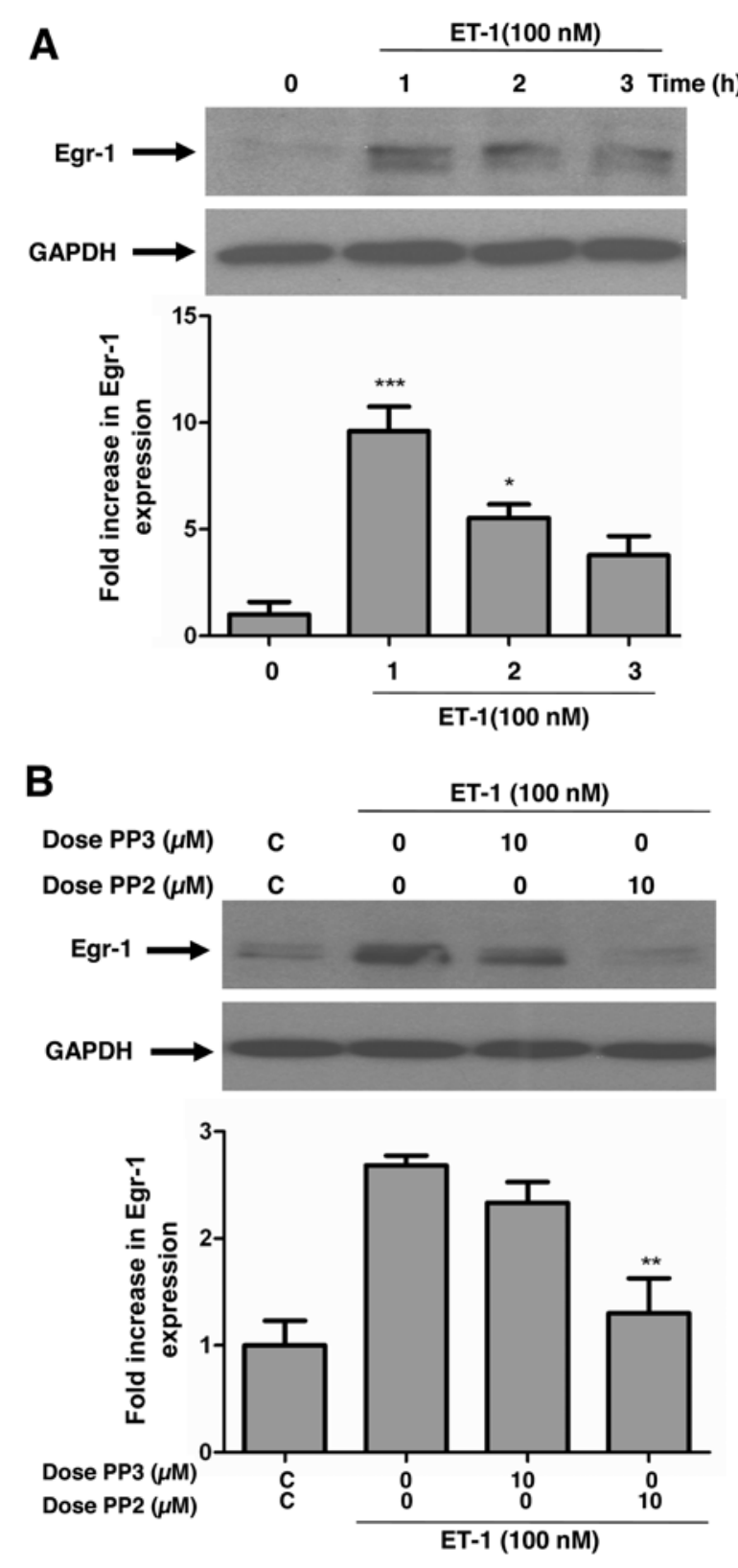

Figure 4. Pharmacological blockade of c-Src attenuates endothelin-1 (ET-1)induced early growth response protein-1 (Egr-1) protein expression in A10 vascular smooth muscle cells (VSMCs). Serum-starved quiescent A10 VSMCs were treated (A) without (0) or with $100 \mathrm{nM}$ ET-1 for the indicated periods of time or (B) were pre-treated in the absence $(0)$ or presence of $10 \mu \mathrm{M}$ PP3 or $10 \mu \mathrm{M}$ PP2 for $30 \mathrm{~min}$, followed by stimulation with ET-1 (100 nM) for $1 \mathrm{~h}$ Nuclear protein was isolated from cell lysates and immunoblotted with Egr-1 antibody as shown in the top panels of each section. Blots were analyzed for total nuclear protein by GAPDH (middle panels of each section). Bottom panels (bar diagrams) represent average data quantified by densitometric scanning of immunoblots showing in the middle panel. Values are the means \pm SE of 3 independent experiments and are expressed as fold increase of protein expression where basal expression observed (C, no stimulation) is defined as 1 . A value of $\mathrm{P}<0.05$ was considered as statistically significant vs. no stimulation (0); or vs. ET-1 stimulation alone in (B). ${ }^{*} \mathrm{P}<0.05,{ }^{* *} \mathrm{P}<0.001$ and ${ }^{* * * *} \mathrm{P}<0.0001$.

or p38 MAPK were observed under these experimental conditions. Furthermore, we used these cells to confirm the role of c-Src in ET-1-induced Egr-1 expression. ET-1-induced Egr-1 expression was blunted in the SYF cells as compared to the $\mathrm{Src}^{+/+}$MEFs, demonstrating the requirement of c-Src in ET-1induced Egr-1 expression (Fig. 5D). 
A
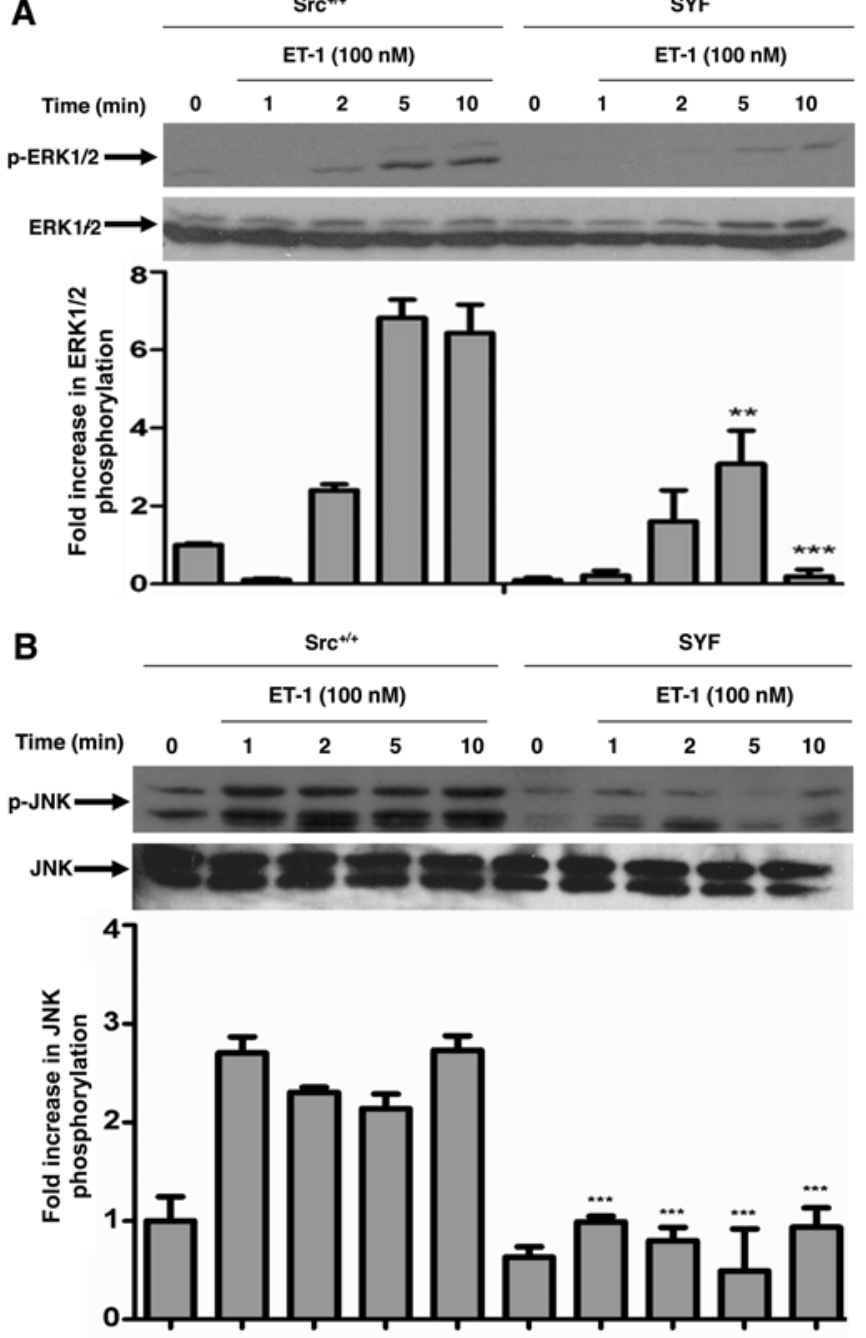

C

\begin{tabular}{|c|c|c|c|c|c|c|c|}
\hline \multicolumn{3}{|c|}{$\mathrm{Src}^{+/+}$} & \multicolumn{5}{|c|}{ SYF } \\
\hline & ET-1 (1 & $n M)$ & & & & $0 \mathrm{r}$ & \\
\hline 0 & 1 & 10 & 0 & 1 & 2 & 5 & 10 \\
\hline
\end{tabular}
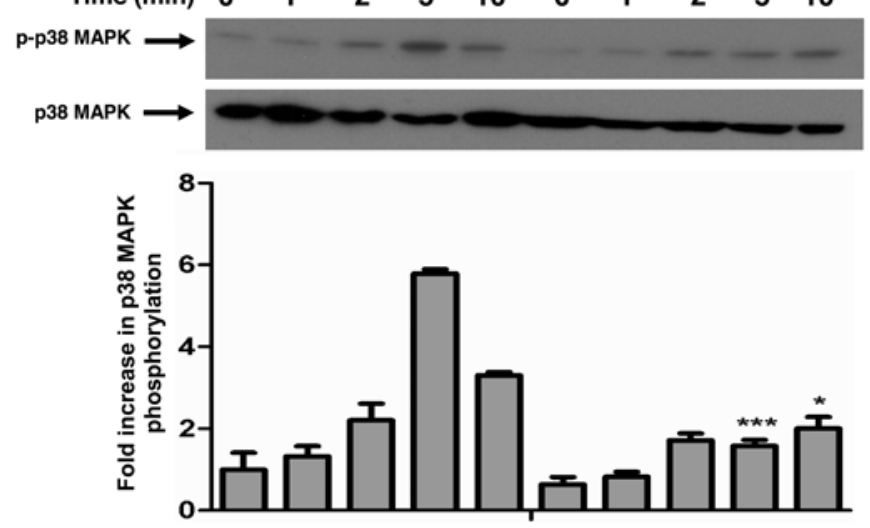

D
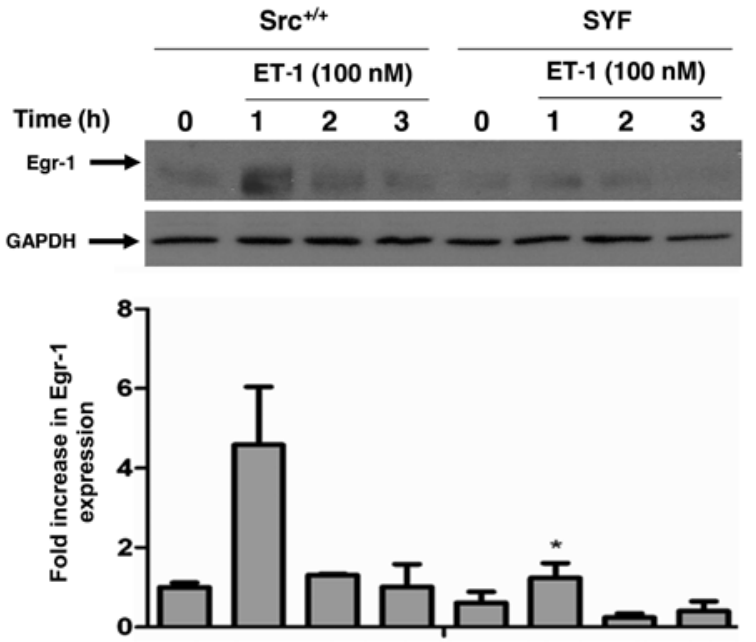

Figure 5.Endothelin-1 (ET-1)-induced extracellular signal-regulated kinase (ERK)1/2,c-Jun N-terminal kinase(JNK) and p38 MAPK phosphorylation, as well as early growth response protein-1 (Egr-1) expression is downregulated in SYF mouse embryonic fibroblasts (MEFs), but not in Src $/^{+}$MEFs. Serum-starved Src ${ }^{+} /^{+}$and SYF MEFs were treated with $100 \mathrm{nMET}-1$ for the indicated periods of time. Cell lysates were subjected to immunoblotting using (A) phospho-specific Thr202/Tyr204-ERK and total ERK antibodies, (B) phospho-specific-Thr183/Tyr185-JNK and total JNK antibodies and (C) phospho-specific-Thr180/Tyr182-p38 MAPK and total p38 MAPK antibodies. (D) To detect Egr-1, nuclear protein was isolated from cell lysates and immunoblotted with Egr-1 antibody and GAPDH. Values are the means \pm SE of 3 independent experiments and are expressed as fold increase of protein expression where basal expression observed (no stimulation) is defined as 1. A value of $\mathrm{P}<0.05$ was considered as statistically significant vs. the corresponding time point stimulations in $\mathrm{Src}^{+} /{ }^{+}$cells. ${ }^{*} \mathrm{P}<0.05,{ }^{* *} \mathrm{P}<0.001$ and ${ }^{* * *} \mathrm{P}<0.0001$.

Pharmacological blockade of ERKI/2 and JNK activity attenuates ET-1-induced Egr-1 expression in A10 VSMCs. In order to further examine whether the attenuation of JNK and ERK $1 / 2$ activity by the inhibition of $\mathrm{c}$-Src plays a role in ET-1-induced Egr-1 expression, we examined the expression of Egr-1 following the pharmacological blockade of ERK1/2 and JNK by using PD98059 and SP600125, respectively. Treatment of the VSMCs with PD98059 or SP600125, respectively, prior to stimulation with ET-1 significantly decreased ET-1-induced Egr-1 expression (Fig. 6). In addition, consistent with the results of the protein expression of Egr-1, the pharmacological blockade of ERK1/2, JNK and c-Src significantly reduced the ET-1-induced upregulation of the Egr-1 mRNA levels (Fig. 7).

\section{Discussion}

c-Src is a member of the Src family of NR-TKs that play a major role in the signaling mechanisms underlying cell differentiation, proliferation, survival, as well as in cell adhesion, morphology and motility (reviewed in ref. 28). Our previous study demonstrated that treatment of VSMCs with ET-1 induced the phosphorylation of Tyr418 in the activation loop of c-Src and the blockade of c-Src activity by PP2 resulted in the inhibition of ET-1 and Ang-II-induced PKB signaling, as well as protein and DNA synthesis (19). However, whether c-Src is also involved inthe ET-1-induced activation of MAPK signaling and subsequent gene expression remains to be established. In the present study, by using a pharmacological approach to inhibit c-Src PTK activity, as well as MEFs deficient in c-Src, we demonstrated that c-Src is essential to propagate ET-1-induced MAPK phosphorylation. In addition, to the best of our knowledge, we also report for the first time that the c-Src-dependent activation of ERK1/2 and JNK is required to induce Egr-1 expression in response to ET-1 in VSMCs. ERK1/2 and JNK, by their ability to phosphorylate several transcription factors and co-activators have been implicated in triggering the transcription of Egr-1 in VSMCs (29-31). For example, c-Jun is a downstream target of JNK and a role of ERK1/2- and JNK-induced c-Jun activity 


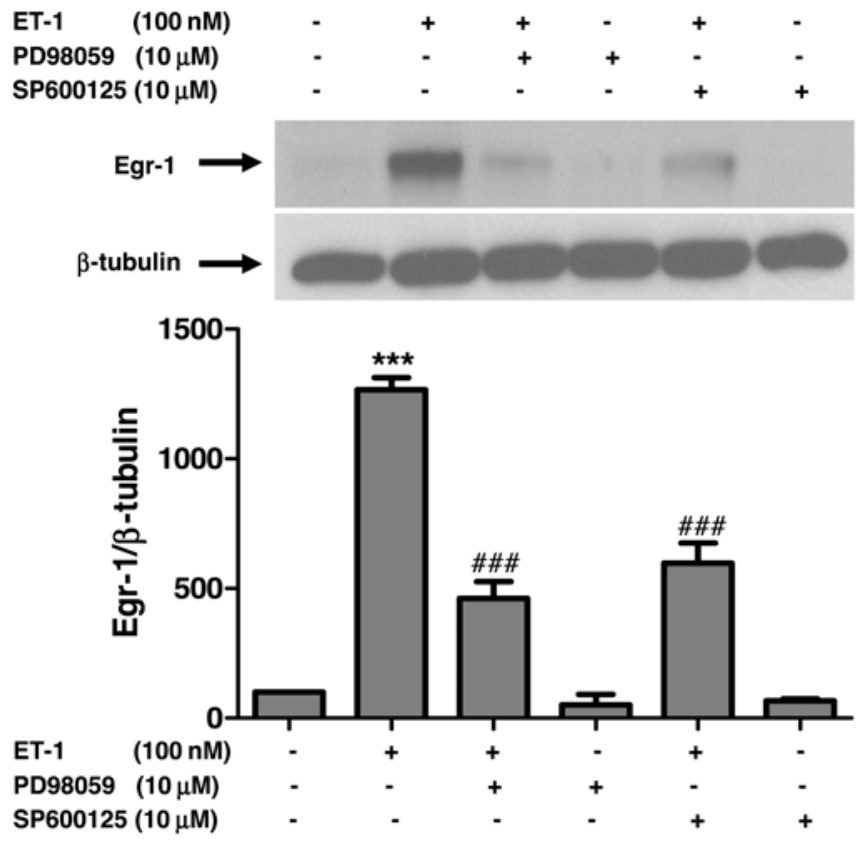

Figure 6. Pharmacological blockade of extracellular signal-regulated kinase (ERK)1/2 and c-Jun N-terminal kinase (JNK) attenuates ET-1-induced early growth response protein-1 (Egr-1) protein expression in A10 vascular smooth muscle cells (VSMCs). Serum-starved quiescent A10 VSMCs were pretreated in the absence (-) or presence (+) of $10 \mu \mathrm{M}$ PD98059 or $10 \mu \mathrm{M}$ SP600125 for $30 \mathrm{~min}$, followed by stimulation with endothelin-1 (ET-1; $100 \mathrm{nM})$ for $1 \mathrm{~h}$. Cell lysates were probed with Egr-1 antibody (top panel) and also analyzed for protein loading, using $\beta$-tubulin (middle panel). Bar diagrams (bottom panels) represent the densitometric quantifications of Egr-1 relative to $\beta$-tubulin. Values are the means \pm SE of 3 independent experiments and expressed as a ratio where the control values are taken as $1 .{ }^{* * *} \mathrm{P}<0.05$ indicates statistical significance vs. no stimulation; or ${ }^{\# \# \#} \mathrm{P}<0.05$ vs. ET-1 stimulation alone.

in shear and injury-induced Egr-1 expression in VSMCs has been demonstrated (32). ERK1/2 also phosphorylates the transcription factor, Ets-like protein-1 (Elk-1) (33), and the c-AMP response element binding protein (CREB) $(33,34)$ both of which have been shown to transcriptionally regulate the expression of Egr-1 in response to various stimuli $(29,31,33,35)$.

Although several studies have reported a requirement of c-Src in MAPK activation in response to vasoactive peptides, growth factors and oxidative stress (22,36-38), its role in ET-1induced activation remains unclear. A lack of c-Src requirement in ET-1-induced MAPK was reported by Yogi et al in VSMCs isolated from mouse mesenteric arteries (22), whereas it was shown to be essential to enhance the MAPK phosphorylation in rat aortic rings treated with ET-1 (37). Our results showing that both the pharmacological blockade of c-Src activity by using PP2 and c-Src deficiency in MEFs resulted in a significant reduction in the ET-1-induced phosphorylation of ERK1/2, JNK and p38 MAPK, support the notion that c-Src is essential to propagate the ET-1 signaling cascade leading to MAPK activation in VSMCs. Consistent with a role of $\mathrm{c}$-Src as a mediator of ET-1-induced responses in VSMCs, it was recently reported that the pharmacological blockade of c-Src not only attenuated the exaggerated levels of ERK1/2 phosphorylation observed in VSMCs from spontaneously hypertensive rats (SHR), but also potently inhibited the aberrant proliferation exhibited by these cells (39). Moreover, an enhanced phosphorylation of c-Src and ERK1/2 in VSMCs isolated from the aorta of SHR

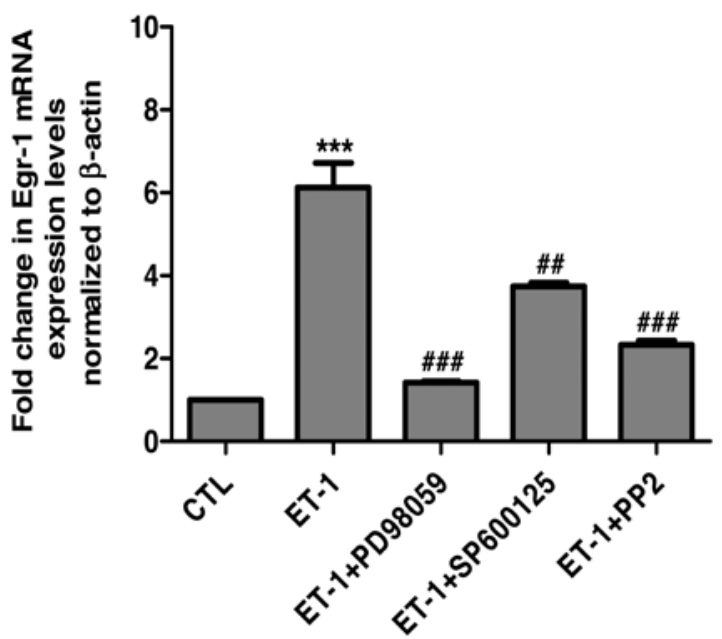

Figure 7. Pharmacological blockade of extracellular signal-regulated kinase (ERK)1/2 and c-Jun N-terminal kinase (JNK) attenuates ET-1-induced upregulation of Egr-1 mRNA levels in A10 vascular smooth muscle cells (VSMCs). Serum-starved quiescent A10 VSMCs were pre-treated in the absence (-) or presence (+) of $10 \mu \mathrm{M}$ PD98059 or $10 \mu \mathrm{M}$ SP600125 for $30 \mathrm{~min}$, followed by stimulation with endothelin-1 (ET-1; $100 \mathrm{nM})$ for $1 \mathrm{~h}$. Analysis of relative Egr-1 mRNA levels was performed by using qPCR. Relative level of Egr-1 mRNA is expressed as fold variation compared to the control and normalized with $\beta$-actin level taken as a standard. Values are the means $\pm \mathrm{SE}$ of 3 independent experiments. ${ }^{* * *} \mathrm{P}<0.05$, indicates statistical significance vs. no stimulation; or ${ }^{\# \#} \mathrm{P}<0.001$ and ${ }^{\# \# \#} \mathrm{P}<0.0001$ vs. ET-1 indicate statistical significance vs. ET-1 stimulation alone.

has been demonstrated (40). These authors also reported that the pharmacological blockade of $\mathrm{c}-\mathrm{Src}$ and ET-1 receptors attenuated the enhanced ERK1/2 phosphorylation, proliferation and growth observed in VSMC sfrom SHR, suggesting the importance of c-Src in mediating ET-1-induced ERK signaling in VSMCs from SHR $(40,41)$.

The results presented herein also reveal a role of c-Src in ET-1-induced Egr-1 expression in VSMCs. Egr-1 belongs to the family of zinc finger transcription factors and plays an important role in vascular proliferative responses (16). Egr-1 governs the expression of several genes that play a deleterious role in vascular biology and has been implicated in intimal thickening in response to vascular injury and the development of atherosclerotic lesions $(13,42)$. ET-1, as well as several growth factors and inflammatory cytokines, has been shown to induce its expression in several cell types including both endothelial cells and VSMCs $(18,20,43-46)$. Our results showing that the pharmacological blockade or genetic knockdown of c-Src inhibits ET-1-induced Egr-1 expression, to our knowledge, represent the first to report a role of c-Src in ET-1-induced Egr-1 expression in VSMCs. Although a role of ERK1/2 and JNK in Egr-1 expression in VSMCs has been reported earlier (47-49), our data are the first to suggest that c-Src functions upstream of MAPK in transducing the effect of ET-1 in the induction of Egr-1 expression in VSMCs.

In conclusion, in this study, we demonstrated that ET-1 induces the phosphorylation of ERK1/2, JNK and p38 MAPK, as well as Egr-1 expression through a c-Src PTK-dependent pathway and tht c-Src-dependent MAPK activation is essential to induce Egr-1 expression in VSMCs. It may be suggested that c-Src is a key upstream intermediate in ET-1-induced signaling pathways leading to Egr-1 expression in VSMCs. 


\section{Acknowledgements}

This study was supported by a grant from the Canadian Institutes of Health Research (MOP 67037) to A.K.S. E.R.S.-C. is a recipient of a studentship from the department of Nutrition, University of Montreal. G.V. was the recipient of Ph.D. studentships from the Faculties of Medicine and Graduate Studies, Université de Montréal and the Montreal Diabetes Research Center (MDRC). The authors would like to thank Ms. Viktoria Youreva for her technical support.

\section{References}

1. Schwartz SM: Smooth muscle migration in atherosclerosis and restenosis. J Clin Invest 100 (Suppl 11): S87-S89, 1997.

2. Cordes KR, Sheehy NT, White MP, Berry EC, Morton SU, Muth AN, Lee TH, Miano JM, Ivey KN and Srivastava D: miR-145 and miR-143 regulate smooth muscle cell fate and plasticity. Nature 460: 705-710, 2009.

3. Iglarz M and Schiffrin EL: Role of endothelin-1 in hypertension. Curr Hypertens Rep 5: 144-148, 2003.

4. Touyz RM and Schiffrin EL: Role of endothelin in human hypertension. Can J Physiol Pharmacol 81: 533-541, 2003.

5. Arai H, Hori S, Aramori I, Ohkubo $\mathrm{H}$ and Nakanishi S: Cloning and expression of a cDNA encoding an endothelin receptor. Nature 348: 730-732, 1990

6. Bouallegue A,Daou GB and Srivastava AK: Endothelin-1-induced signaling pathways in vascular smooth muscle cells. Curr Vasc Pharmacol 5: 45-52, 2007.

7. Seger R and Krebs EG: The MAPK signaling cascade. FASEB J 9: 726-735, 1995

8. Kyosseva SV: Mitogen-activated protein kinase signaling. Int Rev Neurobiol 59: 201-220, 2004.

9. Daou GB and Srivastava AK: Reactive oxygen species mediate endothelin-1-induced activation of ERK1/2, PKB, and Pyk2 signaling, as well as protein synthesis, in vascular smooth muscle cells. Free Radic Biol Med 37: 208-215, 2004.

10. Touyz RM, Yao G, Viel E, Amiri F and Schiffrin EL: Angiotensin II and endothelin-1 regulate MAP kinases through different redox-dependent mechanisms in human vascular smooth muscle cells. J Hypertens 22: 1141-1149, 2004.

11. Daigle C, Martens FM, Girardot D, Dao HH, Touyz RM and Moreau P: Signaling of angiotensin II-induced vascular protein synthesis in conduit and resistance arteries in vivo. BMC Cardiovasc Disord 4: 6, 2004.

12. Bouallegue A,Daou GB and Srivastava AK: Nitric oxide attenuates endothelin-1-induced activation of ERK1/2, PKB, and Pyk2 in vascular smooth muscle cells by a cGMP-dependent pathway. Am J Physiol Heart Circ Physiol 293: H2072-H2079, 2007.

13. Wang TR, Yang G and Liu GN: DNA enzyme ED5 depletes egr-1 and inhibits neointimal hyperplasia in rats. Cardiology 125 192-200, 2013.

14. Cheyou ER, Youreva V and Srivastava AK: Involvement of the early growth response protein 1 in vascular pathophysiology: an overview. Indian J Biochem Biophys 51: 457-466, 2014.

15. Lowe HC, Fahmy RG, Kavurma MM, Baker A, Chesterman CN and Khachigian LM: Catalytic oligodeoxynucleotides define a key regulatory role for early growth response factor- 1 in the porcine model of coronary in-stent restenosis. Circ Res 89: 670-677, 2001

16. Blaschke F, Bruemmer D and Law RE: Egr-1 is a major vascular pathogenic transcription factor in atherosclerosis and restenosis. Rev Endocr Metab Disord 5: 249-254, 2004.

17. Khachigian LM: Early growth response-1 in cardiovascular pathobiology. Circ Res 98: 186-191, 2006.

18. Bouallegue A, Simo Cheyou ER, Anand-Srivastava MB and Srivastava AK: ET-1-induced growth promoting responses involving ERK1/2 and PKB signaling and Egr-1 expression are mediated by $\mathrm{Ca}^{2+} / \mathrm{CaM}$-dependent protein kinase-II in vascular smooth muscle cells. Cell Calcium 54: 428-435, 2013.

19. Bouallegue A, Vardatsikos G and Srivastava AK: Role of insulin-like growth factor 1 receptor and c-Src in endothelin-1- and angiotensin II-induced PKB phosphorylation, and hypertrophic and proliferative responses in vascular smooth muscle cells. Can J Physiol Pharmacol 87: 1009-1018, 2009.
20. Youreva V and Srivastava AK: Early growth response protein-1 expression by insulin-like growth factor-1 requires ROS-dependent activation of ERK1/2 and PKB pathways in vascular smooth muscle cells. J Cell Biochem 117: 152-162, 2016.

21. Huang RP and Adamson ED: The phosphorylated forms of the transcription factor, Egr-1, bind to DNA more efficiently than nonphosphorylated. Biochem Biophys Res Commun 200: 1271-1276, 1994.

22. Yogi A, Callera GE, Montezano AC, Aranha AB, Tostes RC, Schiffrin EL and Touyz RM: Endothelin-1, but not Ang II, activates MAP kinases through c-Src independent Ras-Raf dependent pathways in vascular smooth muscle cells. Arterioscler Thromb Vasc Biol 27: 1960-1967, 2007.

23. Mugabe BE, Yaghini FA, Song CY, Buharalioglu CK, Waters CM and Malik KU: Angiotensin II-induced migration of vascular smooth muscle cells is mediated by p38 mitogen-activated protein kinase-activated c-Src through spleen tyrosine kinase and epidermal growth factor receptor transactivation. J Pharmacol Exp Ther 332: 116-124, 2010.

24. Lowe HC, Chesterman $\mathrm{CN}$ and Khachigian LM: Catalytic antisense DNA molecules targeting Egr-1 inhibit neointima formation following permanent ligation of rat common carotid arteries. Thromb Haemost 87: 134-140, 2002.

25. Harja E, Bucciarelli LG, Lu Y, Stern DM, Zou YS, Schmidt AM and Yan SF: Early growth response-1 promotes atherogenesis: mice deficient in early growth response-1 and apolipoprotein $\mathrm{E}$ display decreased atherosclerosis and vascular inflammation. Circ Res 94: 333-339, 2004.

26. Khachigian LM, Lindner V, Williams AJ and Collins $\mathrm{T}$ : Egr-1-induced endothelial gene expression: a common theme in vascular injury. Science 271: 1427-1431, 1996.

27. Klinghoffer RA, Sachsenmaier C, Cooper JA and Soriano P: Src family kinases are required for integrin but not PDGFR signal transduction. EMBO J 18: 2459-2471, 1999.

28. Roskoski R Jr: Src protein-tyrosine kinase structure and regulation. Biochem Biophys Res Commun 324: 1155-1164, 2004

29. Hasan RN and Schafer AI: Hemin upregulates Egr-1 expression in vascular smooth muscle cells via reactive oxygen species ERK-1/2-Elk-1 and NF-kappaB. Circ Res 102: 42-50, 2008.

30. Thiel G, Mayer SI, Müller I, Stefano L and Rössler OG: Egr-1-A $\mathrm{Ca}(2+)-$-regulated transcription factor. Cell Calcium 47: 397-403, 2010.

31. Cui MZ,Laag E,Sun L,Tan M,Zhao G and Xu X:Lysophosphatidic acid induces early growth response gene 1 expression in vascular smooth muscle cells: CRE and SRE mediate the transcription. Arterioscler Thromb Vasc Biol 26: 1029-1035, 2006.

32. Ni J, Waldman A and Khachigian LM: c-Jun regulates shear-and injury-inducible Egr-1 expression, vein graft stenosis after autologous end-to-side transplantation in rabbits, and intimal hyperplasia in human saphenous veins. J Biol Chem 285: 4038-4048, 2010.

33. Hodge C, Liao J, Stofega M, Guan K, Carter-Su C and Schwartz J: Growth hormone stimulates phosphorylation and activation of elk-1 and expression of $c$-fos, egr-1, and junB through activation of extracellular signal-regulated kinases 1 and 2. J Biol Chem 273: 31327-31336, 1998.

34. Molnar P, Perrault R, Louis S and Zahradka P: The cyclic AMP response element-binding protein (CREB) mediates smooth muscle cell proliferation in response to angiotensin II. J Cell Commun Signal 8: 29-37, 2014

35. Mayer SI and Thiel G: Calcium influx into MIN6 insulinoma cells induces expression of Egr-1 involving extracellular signal-regulated protein kinase and the transcription factors Elk-1 and CREB. Eur J Cell Biol 88: 19-33, 2009.

36. Lieskovska J, Ling Y, Badley-Clarke J and Clemmons DR: The role of Src kinase in insulin-like growth factor-dependent mitogenic signaling in vascular smooth muscle cells. J Biol Chem 281: 25041-25053, 2006.

37. Romero M, Jiménez R, Sánchez M, López-Sepúlveda R, Zarzuelo A, Tamargo J, Pérez-Vizcaíno F and Duarte J: Vascular superoxide production by endothelin-1 requires Src non-receptor protein tyrosine kinase and MAPK activation. Atherosclerosis 212: 78-85, 2010.

38. Mehdi MZ, Pandey NR, Pandey SK and Srivastava AK: $\mathrm{H}_{2} \mathrm{O}_{2}$-induced phosphorylation of ERK1/2 and PKB requires tyrosine kinase activity of insulin receptor and c-Src. Antioxid Redox Signal 7: 1014-1020, 2005.

39. Bou Daou G, Li Y and Anand-Srivastava MB: Enhanced expression of Gia proteins contributes to the hyperproliferation of vascular smooth muscle cells from spontaneously hypertensive rats via MAP kinase- and PI3 kinase-independent pathways. Can J Physiol Pharmacol 94: 49-58, 2016. 
40. Gomez Sandoval YH and Anand-Srivastava MB: Enhanced levels of endogenous endothelin-1 contribute to the over expression of Gi $\alpha$ protein in vascular smooth muscle cells from SHR: role of growth factor receptor activation. Cell Signal 23: 354-362, 2011.

41. Li Y, Lévesque LO and Anand-Srivastava MB: Epidermal growth factor receptor transactivation by endogenous vasoactive peptides contributes to hyperproliferation of vascular smooth muscle cells of SHR. Am J Physiol Heart Circ Physiol 299: H1959-H1967, 2010.

42. Fu M, Zhu X, Zhang J, Liang J, Lin Y, Zhao L, Ehrengruber MU and Chen YE: Egr-1 target genes in human endothelial cells identified by microarray analysis. Gene 315: 33-41, 2003.

43. Kaufmann $\mathrm{K}$ and Thiel G: Epidermal growth factor and platelet-derived growth factor induce expression of Egr-1, a zinc finger transcription factor, in human malignant glioma cells. J Neurol Sci 189: 83-91, 2001.

44. Houston P, Dickson MC, Ludbrook V, White B, Schwachtgen JL, McVey JH, Mackman N, Reese JM, Gorman DG, Campbell C and Braddock M: Fluid shear stress induction of the tissue factor promoter in vitro and in vivo is mediated by Egr-1. Arterioscler Thromb Vasc Biol 19: 281-289, 1999.

45. Yan SF, Lu J, Zou YS, Soh-Won J, Cohen DM, Buttrick PM, Cooper DR, Steinberg SF, Mackman N, Pinsky DJ and Stern DM: Hypoxia-associated induction of early growth response-1 gene expression. J Biol Chem 274: 15030-15040, 1999.
46. Youreva V, Kapakos G and Srivastava AK: Insulin-like growth-factor-1-induced PKB signaling and Egr-1 expression is inhibited by curcumin in A-10 vascular smooth muscle cells. Can J Physiol Pharmacol 91: 241-247, 2013.

47. Day FL, Rafty LA, Chesterman CN and Khachigian LM: Angiotensin II (ATII)-inducible platelet-derived growth factor A-chain gene expression is p42/44 extracellular signal-regulated kinase-1/2 and Egr-1-dependent and mediated via the ATII type 1 but not type 2 receptor. Induction by ATII antagonized by nitric oxide. J Biol Chem 274: 23726-23733, 1999.

48. Morimoto M,KumeN,Miyamoto S,UenoY,KataokaH,Minami M, Hayashida K, Hashimoto N and Kita T: Lysophosphatidylcholine induces early growth response factor-1 expression and activates the core promoter of PDGF-A chain in vascular endothelial cells. Arterioscler Thromb Vasc Biol 21: 771-776, 2001.

49. Iyoda T, Zhang F, Sun L, Hao F, Schmitz-Peiffer C, Xu X and Cui MZ: Lysophosphatidic acid induces early growth response-1 (Egr-1) protein expression via protein kinase CD-regulated extracellular signal-regulated kinase (ERK) and c-Jun N-terminal kinase (JNK) activation in vascular smooth muscle cells. J Biol Chem 287: 22635-22642, 2012. 